\title{
Використання змагальних вправ високої інтенсивності на фоні втоми елітною каратисткою з вадами слуху
}

\author{
Карина Янчук \\ Олександр Тихорський \\ Олександр Володченко \\ Вікторія Худякова
}

Харківська державна академія фізичної культури, Харків, Україна

\begin{abstract}
Мета: визначити ефективність використання змагальних вправ з високою швидкістю на фоні втоми елітною каратисткою з вадами слуху протягом чотирирічного циклу.

Матеріал і методи: у дослідженні брала участь спортсменка з вадами слуху, що займається карате - Дефлімпійська чемпіонка 2013 та 2017 років. . У тренувальному процесі спортсменка використовувала змагальні вправи високої інтенсивності на фоні втоми наприкінці тренувального заняття. Для визначення ефективності програми у дослідженні використовувався ряд психофізіологічних показників, а саме: ефективність роботи, психічна стійкість, час простої реакції на світло, реакція на предмет, що рухається, теппінг-тест, час реакції вибору, проба Ромберга, концентрація та переключення уваги. Також досліджувалась кількість нанесених ударів у різних частинах поєдинку.

Результати: достовірне покращення результатів за час чотирирічного циклу спостерігалося у показниках психічної стійкості $(t=2,02 ; p<0,05)$, часу простої реакції на світло ( $t=2,51 ; p<0,05)$, реакції на предмет, що рухається $(t=3,79 ; p<0,001)$, частоти рухів $(t=3,63 ; p<0,001)$, часу реакції вибору $(t=2,08 ; p<0,05)$, проби Ромберга $(t=6,96$; $p<0,001)$, у переключенні уваги за тестом Бурдона $(t=2,40 ; p<0,05)$. У показнику концентрації уваги та ефективності роботи на таблицях Шульте статистично значимих відмінностей не було виявлено $(p>0,05)$.

Висновки: виявлено покращення результативності спортсменки при виконанні атакуючих дій протягом других та третіх 40 с поєдинку. Зазначене свідчить про розвиток спеціальної витривалості та підвищення працездатності на фоні втоми. Отримані результати підтверджуються покращенням психофізіологічних показників, що впливають на спортивну результативність у карате. Доведено доцільність використання змагальних вправ на фоні втоми та їх вплив на психофізіологічні показники Дефлімпійської чемпіонки з карате.
\end{abstract}

Ключові слова: карате, психофізіологічні показники, атакуючі дії, елітна спортсменка, каратистка з вадами слуху.

\section{Вступ}

При розробці тренувальних програм для спортсменів з вадами слуху слід враховувати психофізіологічні показники, здатність до адаптації у соціальній сфері, здатність до співпраці з оточуючими $[4,8]$. За даними вчених, деякі параметри, що характеризують фізичну працездатність у спортсменів з вадами слуху вдвічі нижчі, ніж у здорових, незважаючи на те, що фізична працездатність корелює з адаптацією організму до виконання роботи при заданих параметрах швидкості, тривалості роботи $[2,9,12]$.

Актуальними психофізіологічними показниками у карате $€$ ті, що пов'язані з фізичними якостями, які проявляються спортсменами під час поєдинку та тренувальної діяльності $[10,11]$. Рухові якості тісно пов'язані з особливостями нервової системи людини: силою-слабкістю, рухливістю-інертністю, врівноваженістю - неврівноваженістю нервових процесів [3]. Кожна рухлива якість забезпечується декількома типологічними особливостями нервової системи. Також від психофізіологічних особливостей залежить швидкість настання втоми спортсменок під час тренувальних занять та змагань $[5,6]$.
Відомо, що спортсмени в карате зокрема та в єдиноборствах в цілому, втомлюючись під час поєдинку, гірше тримають рівновагу та бойову стійку, знижується точність нанесення ударів [7]. Це, безперечно, негативно впливає як на проведення атакуючих дій, так і на захисні дії. Спортсмени, що краще протистоять втомі під час навантажень мають перевагу наприкінці двобоїв. Під впливом тренування на фоні втоми відмічається покращення систем підтримки статичної та динамічної рівноваги під час поєдинку.

Спортсмени-єдиноборці з вадами слуху відстають від здорових колег у розвитку швидкісно-силових якостей та точності виконання рухових дій. Спортсмени з вадами слуху швидше втомлюються при виконанні фізичних вправ [1]. При побудові тренувальних програм для спортсменів з вадами слуху слід враховувати індивідуальні психофізіологічні особливості, функціональні особливості а також особистісні характеристики [13].

Під час аналізу науково-методичної літератури нами не було виявлено досліджень щодо впливу психофізіологічних показників спортсменів з вадами слуху на їх змагальну результативність. 
Мета дослідження - визначити ефективність використання змагальних вправ з високою швидкістю на фоні втоми елітною каратисткою з вадами слуху протягом чотирирічного циклу.

\section{Матеріал і методи дослідження}

У дослідженні брала участь спортсменка з вадами слуху, що займається карате - Дефлімпійська чемпіонка 2013 та 2017 років. Дослідження проводилось протягом чотирирічного циклу підготовки до Дефлімпійських ігор 2017 року. У тренувальному процесі спортсменка використовувала змагальні вправи високої інтенсивності на фоні втоми наприкінці тренувального заняття. Каратистка використовувала вправи із застосуванням спорядження, що використовується в карате (вправи 3 грушами та маківарами, настінною подушкою, відпрацювання ударів з партнером).

У дослідженні використовувався ряд психофізіологічних показників, а саме: ефективність роботи, психічна стійкість, час простої реакції на світло, реакція на предмет, що рухається, теппінг-тест, час реакції вибору, проба Ромберга, концентрація та переключення уваги. Також досліджувалась кількість нанесених ударів у різних частинах поєдинку.

\section{Результати дослідження}

При побудові чотирирічного циклу підготовки спортсменки до Дефлімпійських ігор враховувалися її індивідуальні показники. Заняття з використанням тренування швидкості на фоні складається традиційно з трьох частин - підготовчої, основної та заключної. Спортсменка використовувала засоби, що є загальноприйнятими в карате: відпрацювання техніки ударів руками та ногами у верхній сектор (Чудан), відпрацювання блоків та захисних дій, спаринги з партнерами, вправи на розвиток витривалості та вправи на розтягування (табл. 1).

Наприкінці заняття в програму тренувального заняття були включені вправи на розвиток швидкості на фоні втоми. Робота проводилась на мішках та маківарі з максимально можливою швидкістю та з мінімальним часом відпочинку між серіями. Використовувалися лише тех- нічно добре відпрацьовані вправи та серії вправ. Переважна спрямованість роботи наприкінці заняття проводилась у діапазоні від змішаної зони аеробно-анаеробної (ЧСС - 175-185 уд/хв) до анаеробної гліколітичної (ЧСС - 200 уд/хв). Подібні заняття проводились в ударних мікроциклах у підготовчих та змагальних періодах підготовки та складали велику частку від усіх тренувальних занять.

Для аналізу змін психофізіологічних показників елітної спортсменки з вадами слуху протягом чотирирічного циклу ми порівняли їх на початку та наприкінці підготовки. Кожен з показників тестувався 24 рази. Для тестування обирались дні відновного мікроциклу, коли спортсменка знаходилась у оптимальній формі та не була втомлена. Всього було проаналізовано 10 показників. Отримані дані представлено у табл. 2.

Достовірне покращення результатів спостерігалося у показниках психічної стійкості $(\mathrm{t}=2,17$; $\mathrm{p}<0,05)$, часу простої реакції на світло $(\mathrm{t}=2,51 ; \mathrm{p}<0,05)$, реакції на предмет, що рухається ( $t=3,79 ; p<0,001)$, частоти рухів $(t=3,63 ; p<0,001)$, часу реакції вибору $(t=2,21 ; p<0,05)$, проби Ромберга ( $t=6,96 ; p<0,001)$, переключення уваги за тестом Бурдона $(t=2,40 ; p<0,05)$. У показнику концентрації уваги та ефективності роботи на таблицях Шульте статистично значимих відмінностей не було виявлено $(\mathrm{p}>0,05)$.

Для визначення ефективності роботи каратисток 3 вадами слуху у різних частинах поєдинку була досліджена кількість атакуючих дій протягом перших, других та останніх 40 с поєдинку. Дані представлені у табл. 3.

Так, прослідковується статистично значиме зниження кількості ударів в середині та наприкінці поєдинку, що викликане втомою спортсменки. Протягом перших 40 с спортсменка показала результат 6,29 0,66 атакуючих

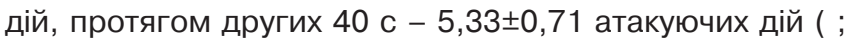
$\mathrm{p}<0,001)$.

Для дослідження впливу авторської методики на спортивну результативність спортсменки з вадами слуху було порівняно кількість нанесених ударів на початку та наприкінці дослідження у різних частинах поєдинку (табл. 4).

Таблиця 1

Зміст тренувального заняття для розвитку швидкісних якостей на фоні втоми

\begin{tabular}{|l|l|l|}
\hline $\begin{array}{c}\text { Частина } \\
\text { заняття }\end{array}$ & \multicolumn{1}{|c|}{ Засоби тренування } & Чac, хв \\
\hline Підготовча & $\begin{array}{l}\text { Привітання } \\
\text { Розминка }\end{array}$ & 15 \\
\hline Основна & Комплекс вправ на розвиток спеціальної витривалості & 10 \\
& Комплекс вправ на розтягування м’язів & 10 \\
& Відпрацювання техніки ударів ногами та руками у сектор Чудан & 15 \\
& Відпрацювання блоків та захисних дій & 15 \\
& Спаринги з партнерами & 15 \\
& Робота на мішках та маківарі з максимальною щвидкістю & 10 \\
\hline Заключна & Вправи на відновлення дихання & 3 \\
& Вправи на розслаблення м'язів & 5 \\
\hline Загалом час тренувального заняття & 98 \\
\hline
\end{tabular}


Таблиця 2

Порівняння психофізіологічних показників Дефлімпійської чемпіонки з карате на початку та наприкінці чотирирічного циклу

\begin{tabular}{|c|c|c|c|c|c|c|c|c|}
\hline \multirow[t]{2}{*}{ Показник } & \multicolumn{3}{|c|}{ 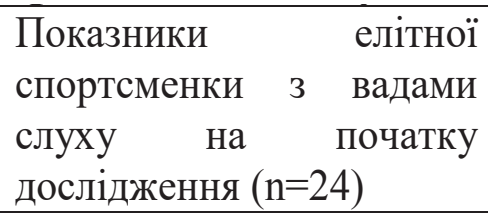 } & \multicolumn{3}{|c|}{ 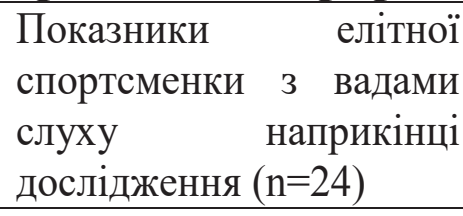 } & \multirow[t]{2}{*}{$\mathrm{t}$} & \multirow[t]{2}{*}{$\mathrm{p}$} \\
\hline & $\overline{X_{1}}$ & \pm & $\sigma_{1}$ & $\overline{X_{2}}$ & \pm & $\sigma_{2}$ & & \\
\hline $\begin{array}{l}\text { Ефективність } \\
\text { роботи за тестом } \\
\text { Шульте, ум.од. }\end{array}$ & 65,0 & \pm & 1,6 & 64,1 & \pm & 0,9 & 1,47 & $>0,05$ \\
\hline $\begin{array}{l}\text { Психічна } \\
\text { стійкість } \\
\text { тестом Ша } \\
\text { ум.од. }\end{array}$ & 1,00 & \pm & 0,05 & 0,96 & \pm & 0,04 & 2,17 & $<0,05$ \\
\hline $\begin{array}{l}\text { Час простої } \\
\text { реакції на світло, } \\
\text { с }\end{array}$ & 0,28 & \pm & 0,01 & 0,26 & \pm & 0,03 & 2,51 & $<0,05$ \\
\hline $\begin{array}{lr}\text { Реакція } & \text { на } \\
\text { предмет, } & \text { що } \\
\text { рухається, с } & \end{array}$ & 0,51 & \pm & 0,03 & 0,49 & \pm & 0,02 & 3,79 & $<0,001$ \\
\hline $\begin{array}{l}\text { Теппінг-тест, } \\
\text { частота рухів }\end{array}$ & 4,88 & \pm & 0,19 & 5,03 & \pm & 0,12 & 3,63 & $<0,001$ \\
\hline $\begin{array}{ll}\text { Час реакції } \\
\text { вибору, с }\end{array}$ & 1,17 & \pm & 0,10 & 1,12 & \pm & 0,08 & 2,21 & $<0,05$ \\
\hline $\begin{array}{l}\text { Проба Ромберга, } \\
\text { с }\end{array}$ & 10,2 & \pm & 0,86 & 12,2 & \pm & 1,09 & 6,96 & $<0,001$ \\
\hline $\begin{array}{l}\text { Концентрація } \\
\text { уваги за тестом } \\
\text { Бурдона, ум. од }\end{array}$ & 241,9 & \pm & 8,7 & 244,9 & \pm & 5,56 & 1,46 & $>0,05$ \\
\hline $\begin{array}{l}\text { Переключення } \\
\text { уваги за тестом } \\
\text { Бурдона, ум. од }\end{array}$ & 32,5 & \pm & 1,7 & 31,4 & \pm & 1,5 & 2,40 & $<0,05$ \\
\hline
\end{tabular}

Таблиця 3 Показники кількості нанесених ударів на початку, в середині та наприкінці двобою (n поєдинків = 14) на початку дослідження

\begin{tabular}{|c|c|c|c|c|}
\hline \multirow{2}{*}{ Частина поєдинку } & \multicolumn{3}{|c|}{ Кількість атакуючих дій } & \multirow{2}{*}{$\mathrm{t} ; \mathrm{p}$} \\
\hline & $\bar{X}$ & \pm & $\sigma$ & \\
\hline Перші 40 c & 6,29 & \pm & 0,66 & \multirow{3}{*}{$\begin{array}{c}t_{I-I I}=3,71 ; \mathrm{p}<0,001 \\
t_{I I-I I I}=6,91 ; \mathrm{p}<0,001 \\
t_{I-I I}=11,04 ; \mathrm{p}<0,001\end{array}$} \\
\hline Другі 40 с & 5,33 & \pm & 0,71 & \\
\hline Треті 40 c & 3,53 & \pm & 0,65 & \\
\hline
\end{tabular}




\begin{abstract}
Таблиця 4
Порівняння кількості нанесених ударів досліджуваною спортсменкою у різних частинах двобою (n поєдинків $=14$ ) на початку та наприкінці дослідження
\end{abstract}

\begin{tabular}{|c|c|c|c|c|c|c|c|c|}
\hline \multirow{2}{*}{$\begin{array}{l}\text { Частина } \\
\text { поєдинку }\end{array}$} & \multicolumn{3}{|c|}{$\begin{array}{l}\text { Кількість атакуючих дій } \\
\text { на початку дослідження }\end{array}$} & \multicolumn{3}{|c|}{$\begin{array}{l}\text { Кількість атакуючих дій } \\
\text { наприкінці дослідження }\end{array}$} & \multirow[t]{2}{*}{$\mathrm{t}$} & \multirow{2}{*}{$\mathrm{p}$} \\
\hline & & \pm & $\sigma$ & $\bar{X}$ & \pm & $\sigma$ & & \\
\hline Перші 40 c & 6,29 & \pm & 0,66 & 6,71 & \pm & 1,24 & 1,10 & $>0,05$ \\
\hline Другі 40 с & 5,33 & \pm & 0,71 & 6,16 & \pm & 1,02 & 3,61 & $<0,01$ \\
\hline Треті 40 с & 3,53 & \pm & 0,65 & 5,69 & \pm & 1,72 & 4,38 & $<0,001$ \\
\hline
\end{tabular}

Так, статистично значимі відмінності було виявлено в середині поєдинку, протягом других 40 с (t=3,61; $\mathrm{p}<0,01)$ та наприкінці поєдинку, протягом третіх $40 \mathrm{c}$ $(t=4,38 ; p<0,001)$.

\section{Висновки / Дискусія}

За чотирирічний цикл було виявлено прогрес у більшості показників психофізіологічного стану спортсменки з вадами слуху. Дані показники мають безпосередній вплив на тренувальну та змагальну діяльність в карате. Покращення психофізіологічних показників свідчить про підвищення рівня спортивної форми елітної спортсменки та показує, що наприкінці чотирирічного циклу вона знаходилась в оптимальному психологічному та фізіологічному стані.

Отримані результати дозволяють розширити знання щодо підготовки спортсменок з вадами слуху до змагань найвищого рівня. Доведено доцільність використання змагальних вправ на фоні втоми та їх вплив на психофізіологічні показники Дефлімпійської чемпіонки з карате.

Виявлено покращення результативності спортсменки при виконанні атакуючих дій протягом других та третіх 40 с поєдинку. Зазначене свідчить про розвиток спеціальної витривалості та підвищення працездатності на фоні втоми. Отримані результати підтверджуються покращенням психофізіологічних показників, що впливають на спортивну результативність у карате (психічна стійкість, час простої реакції на світло, реакція на предмет, що рухається, частота рухів, час реакції вибору, проба Ромберга, переключення уваги за тестом Бурдона).

Перспективи подальших досліджень полягають у визначенні кореляційного взаємозв'язку між психофізіологічними показниками та показниками швидкості нанесення ударів у карате.

Конфлікт інтересів. Автори заявляють, що відсутній конфлікт інтересів, який може сприйматись таким, що може завдати шкоди неупередженості статті.

Джерела фінансування. Ця стаття не отримала фінансової підтримки від державної, громадської або комерційної організації.

\title{
Список посилань
}

1. Мішин М., Петренко І., Кийко А. (2020), «Оптимізація процесу фізичної підготовки 10-11-річних спортсменів $з$ вадами слуху, які займаються джиу-джитсу», Слобожанський науково-спортивний вісник, №4 (78), C. 17-23, doi:10.15391/snsv.2020-4.003

2. Тихорський О. (2016), «Особливості побудови тренувального процесу висококваліфікованих бодібілдерів в змагальному періоді підготовки», Педагогіка, психологія та медико-біологічні проблеми фізичного виховання і спорту, №6, С. 26-34

3. Шестак Ю., Мулик В., Окунь Д. (2020), «Вплив використання спеціальних вправ на психофізіологічні показники юних боксерів 15-16 років», Слобожанський науково-спортивний вісник, № 6 (80), C. 46-51, doi:10.15391/snsv.2020-6.007

4. Янчук К., Тихорський О., Півень О. (2021), «Морфо-функціональні особливості каратисток з вадами слуху», Збірник наукових праць SCIENTIA. URL: https://ojs.ukrlogos.in.ua/index.php/scientia/article/view/13608

5. Янчук К., Тихорський О., Петренко І. (2020), «Аналіз ударних прийомів каратисток високої кваліфікації з вадами слуху», Слобожанський науково-спортивний вісник, № 2(76), С. 91-103, doi:10.15391/snsv.2020-2.006

6. Gbler M. (2017), «The Evaluation of balance performance for elite male karate athletes after fatigue», International Journal of Sport Exercise and Training Sciences-IJSETS, T. 3., №. 4, pp. 161-168.

7. Hadad A. (2020), «Postural control in karate practitioners: Does practice make perfect?», Gait \& posture, №77, pp. 218-224.

8. Herrera-Valenzuela T. (2019), «Physiological responses of elite karate athletes during simulated competition», Ido Movement for Culture. Journal of Martial Arts Anthropology, №. 4, pp. 45-50.

9. Koropanovski N. (2011), «Anthropometric and physical performance profiles of elite karate kumite and kata competitors», Journal of human kinetics, №.30, pp. 107-121.

10. Piepiora P., Kazimierz W., Piepiora Z. (2018), «Personality profiles of karate masters practising different kumite styles», Archives of Budo, №14, pp. 87-101.

11. Sбnchez-Puccini M. (2014), "Anthropometric and physical fitness characterization of male elite karate athletes», Int. J. Morphol, №. 3. C. 1026-1031.

12. Urbinati K. (2017), «Physiological and biomechanical fatigue responses in Karate: A case study», The Open Sports Sciences Journal, №. 1, pp. 10-22.

13. Vuljanić A., Tiљma D., Miholić S. J (2017), «Sports-Anamnesis Profile of Deaf Elite Athletes in Croatia», 8th International Scientific Conference on Kinesiology, the University of Zagreb, pp. 102-112.

Стаття надійшла до редакції: 03.08.2021 р.

Опубліковано: 31.08.2021 p. 


\title{
СЛОБОЖАНСЬКИЙ НАУКОВО-СПОРТИВНИЙ ВІСНИК
}

\begin{abstract}
Аннотация. Янчук Карина, Александр Тихорский, Александр Володченко, Виктория Худякова. Использование соревновательных упражнений высокой интенсивности на фоне усталости элитной каратисткой с нарушениями слуха. Цель: определить эффективность использования соревновательных упражнений с высокой скоростью на фоне усталости элитной каратисткой с проблемами слуха в течение четырехлетнего цикла. Материал и методы: в исследовании приняла участие спортсменка с нарушениями слуха, занимающаяся каратэ - дефлимпийская чемпионка 2013 и 2017 гг. В тренировочном процессе спортсменка использовала соревновательные упражнения высокой интенсивности на фоне усталости в конце тренировочного занятия. Для определения эффективности программы в исследовании использовался ряд психофизиологических показателей, а именно: эффективность работы, психическая устойчивость, время простой реакции на свет, реакция на движущийся предмет, теппинг-тест, время реакции выбора, проба Ромберга, концентрация и переключение внимания. Также исследовалась количество нанесенных ударов в разных частях поединка. Результаты: достоверное улучшение результатов наблюдалось в показателях: психической устойчивости $(t=2,02 ; p<0,05)$, времени простой реакции на свет $(t=2,51 ; p<0,05)$, реакции на движущийся предмет $(t=3,79 ; p<0,001)$, частоты движений $(t=3,63 ; p<0,001)$, времени реакции выбора $(t=2,08 ; p$ $<0,05)$, пробы Ромберга $(t=6,96 ; p<0,001)$, переключения внимания в тесте Бурдона $(t=2,40 ; p<0,05)$. В показателях концентрации внимания и эффективности работы на таблицах Шульте статистически значимых различий не было выявлено ( $p>0,05)$. Выводы: выявлено улучшение результативности спортсменки при выполнении атакующих действий в течение вторых и третьих 40 с поединка. Указанное свидетельствует о развитии специальной выносливости и повышения работоспособности на фоне усталости. Полученные результаты подтверждаются улучшением психофизиологических показателей, влияющих на спортивную результативность в каратэ. Доказана целесообразность использования соревновательных упражнений на фоне усталости и их влияние на психофизиологические показатели Дефлимпийской чемпионки по каратэ.
\end{abstract}

Ключевые слова: каратэ, психофизиологические показатели, атакующие действия, элитная спортсменка, каратистка с нарушениями слуха.

Abstract. Karyna lanchuk, Oleksandr Tykhorskyi, Oleksandr Volodchenko, Victoria Khudiakova. Use of high-intensity competitive exercises against the background of fatigue by an elite karateka with hearing impairments. Purpose: to determine the effectiveness of the use of competitive exercises at high speed on the background of fatigue elite karate with hearing impairments during a four-year cycle. Materials and methods: the study involved an athlete with hearing impairments, engaged in karate Deaflympic champion in 2013 and 2017. In the training process, the athlete used high-intensity competitive exercises against the background of fatigue, at the end of the training session. To determine the effectiveness of the program in the study used a number of psychophysiological indicators, such as: work efficiency, mental stability, time of simple reaction to light, reaction to a moving object, tapping test, reaction time of choice, Romberg test, concentration and switching of attention. The number of blows in different parts of the match was also investigated. Results: significant improvement of results was observed in the indicator of mental stability ( $t=2.02 ; p$ $<0.05)$, time of simple reaction to light $(t=2.51 ; p<0.05)$, reaction to a moving object $(t=3.79 ; p<0.001)$, frequency of movements $(t=$ 3.63; $p<0.001)$, choice reaction time $(t=2.08 ; p<0.05)$, Romberg test $(t=6.96 ; p<0.001)$, switching attention according to the Bourdon test $(t=2.40 ; p<0.05)$. No statistically significant differences were found in the indicator of concentration of attention and efficiency of work on Schulte's tables ( $p>0.05$ ). Conclusions: there was an improvement in the performance of the athlete when performing offensive actions during the second and third 40 seconds of the fight. This indicates the development of special endurance and increased efficiency against the background of fatigue. The obtained results are confirmed by the improvement of psychophysiological indicators that affect sports performance in karate. The expediency of using competitive exercises against the background of fatigue and their influence on the psychophysiological parameters of the Deaflympic karate champion is proved.

Keywords: karate, psychophysiological indicators, attacking actions, elite sportswoman, karate player with hearing impairments.

\section{References}

1. Mishin, M., Petrenko, I., Kiyko, A. (2020), «Optimization of the process of physical training of 10-11-year-old hearing-impaired athletes engaged in jiu-jitsu», Slobozhansky scientific and sports herald, №4 (78), pp. 17-23, doi: 10.15391 / snsv.2020-4.003 (in Ukr.).

2. Tykhorskyi, O. (2016), «Peculiarities of building the training process of highly qualified bodybuilders in the competitive period of training», Pedagogy, psychology and medical and biological problems of physical education and sports, №6, pp. 26-34 (in Ukr.).

3. Shestak, Yu., Mulyk, V., Okun, D. (2020), «The impact of the use of special exercises on the psychophysiological parameters of young boxers 15-16 years», Slobozhansky scientific and sports herald, № 6 (80), pp. 46-51, doi: 10.15391 / snsv.2020-6.007 (in Ukr.).

4. Ianchuk, K., Tykhorskyi, O., Piven, O. (2021), «Morpho-functional features of karate girls with hearing impairments», Collection of scientific works SCIENTIA. URL: https://ojs.ukrlogos.in.ua/index.php/scientia/article/view/13608 (in Ukr.).

5. Ianchuk, K., Tykhorskyi, O., Petrenko, I. (2020), «Analysis of percussion techniques of highly qualified karatekas with hearing impairments», Slobozhansky Scientific and Sports herald, № 2 (76), pp. 91-103, doi: 10.15391 / snsv.2020-2.006 (in Ukr.).

6. Güler, M. (2017), «The Evaluation of balance performance for elite male karate athletes after fatigue», International Journal of Sport Exercise and Training Sciences-IJSETS, T. 3., №. 4, pp. 161-168. (in Eng.).

7. Hadad, A. (2020), «Postural control in karate practitioners: Does practice make perfect?», Gait \& posture, №77, pp. 218-224. (in Eng.).

8. Herrera-Valenzuela, T. (2019), «Physiological responses of elite karate athletes during simulated competition», Ido Movement for Culture. Journal of Martial Arts Anthropology, №. 4, pp. 45-50. (in Eng.).

9. Koropanovski, N. (2011), «Anthropometric and physical performance profiles of elite karate kumite and kata competitors», Journal of human kinetics, №.30, pp. 107-121. (in Eng.).

10. Piepiora, P., Kazimierz, W., Piepiora, Z. (2018), «Personality profiles of karate masters practising different kumite styles», Archives of Budo, №14, pp. 87-101. (in Eng.).

11. Sánchez-Puccini, M. (2014), "Anthropometric and physical fitness characterization of male elite karate athletes», Int. J. Morphol, №. 3. C. 1026-1031. (in Eng.).

12. Urbinati K. (2017), «Physiological and biomechanical fatigue responses in Karate: A case study», The Open Sports Sciences Journal, №. 1, pp. 10-22. (in Eng.).

13. Vuljanić A., Tiљma D., Miholić S. J (2017), "Sports-Anamnesis Profile of Deaf Elite Athletes in Croatia», 8th International Scientific Conference on Kinesiology, the University of Zagreb, pp. 102-112. (in Eng.).

Received: 03.08.2021.

Published: 31.08.2021. 


\section{СЛОБОЖАНСЬКИЙ НАУКОВО-СПОРТИВНИЙ ВІСНИК}

\section{Відомості про авторів / Information about the Authors}

Янчук Карина Олегівна: аспірантка; Харківська державна академія фізичної культури: вул. Клочківська 99, м. Харків, 61058, Україна.

Янчук Карина Олеговна: аспирантка; Харьковская государственная академия физической культуры: ул. Клочковская 99 г. Харьков, 61058, Украина.

Karyna lanchuk: graduate student; Kharkiv state Academy of Physikal Culture: Klochkivska str. 99, Kharkiv, 61058, Ukraine.

ORCID: https://orcid.org/0000-0002-3481-346X

E-mail: karina.yanchuk@gmail.com

Тихорський Олександр Анатолійович: к. фіз. вих.; Харківська державна академія фізичної культури: вул. Клочківська 99, м. Харків, 61058, Україна.

Тихорский Александр Анатольевич: к.физ. восп.; Харьковская государственная академия физической культуры: ул. Клочковская 99, г. Харьков, 61058, Украина.

Oleksandr Tykhorskyi: PhD (Physical Education and Sport); Kharkiv state Academy of Physikal Culture: Klochkivska str. 99, Kharkiv, 61058, Ukraine.

ORCID: https://orcid.org/0000-0003-1779-0849

E-mail: tihorskiialeks@gmail.com

Володченко Олександр Анатолійович: к. фіз. вих.; Харківська державна академія фізичної культури: вул. Клочківська 99, м. Харків, 61058, Україна.

Володченко Александр Анатольевич: к.физ. восп.; Харьковская государственная академия физической культуры: ул. Клочковская 99, г. Харьков, 61058, Украина.

Oleksandr Volodchenko: PhD (Physical Education and Sport); Kharkiv state Academy of Physikal Culture: Klochkivska str. 99, Kharkiv, 61058, Ukraine.

ORCID: https://orcid.org/0000-0002-1189-3524

E-mail: kh_alex.kick@ukr.net

Худякова Вікторія Борисівна: к. фіз. вих.; Харківська державна академія фізичної культури: вул. Клочківська 99, м. Харків, 61058, Україна.

Худякова Виктория Борисовна: к.физ. восп.; Харьковская государственная академия физической культуры: ул. Клочковская 99, г. Харьков, 61058, Украина.

Victoria Khudiakova: PhD (Physical Education and Sport); Kharkiv state Academy of Physikal Culture: Klochkivska str. 99, Kharkiv, 61058, Ukraine.

ORCID: https://orcid.org/0000-0003-1376-6761

E-mail: vitochka2004@hotmail.com 